\title{
Design of Coal Mine Intelligent Monitoring System based on ZigBee Wireless Sensor Network
}

\author{
Gao Dan ${ }^{1, a}$, Li Weiwei ${ }^{1, b}$ and Dai Kun ${ }^{1, c}$ \\ ${ }^{1}$ Department of Automation Engineering, Tangshan Polytechnic College, Tangshan, 063200, China \\ a495403374@qq.com, b491321914@qq.com, '395745402@qq.com
}

Keywords: ZigBee, Intelligent control, Monitor.

\begin{abstract}
This paper introduces the overall architecture of coal mine intelligent monitoring system. Focusing on two key issues of intelligent control and ZigBee wireless sensor networks were studied. Coal mine intelligent monitoring system can be used to monitor the concentration of carbon monoxide, carbon dioxide concentration, oxygen concentration, wind speed, air pressure, smoke, temperature and etc.. Sensor data are transmitted by the ZigBee wireless sensor network to the monitor host machine which using intelligent control scheme to make control decisions. The system can be used to monitor to coal mine. The operation of system has the very high actual effect.
\end{abstract}

\section{Introduction}

In recent years, the coal mine accidents have frequently occurred. According to incomplete statistics, in recent years, China's coal production accounts for $35 \%$ of world output, but the accident casualties is $80 \%$ of the world the number of casualties. It causes economic losses, or causing casualties. Security problem has become the key issues in the coal mine production. Accident prevention is the focus of the current work in the coal mine. Coal mine monitoring system is more and more important to realize the environmental parameters such as carbon monoxide, temperature, wind speed and so on. They play an important role in coal mine safety production.

Currently the systems used in most cases are lack of flexibility, less intelligence and integration technology application. System cannot meet the daily needs of coal mine. Technological innovation is imperative. Wireless sensor network is data collection network of wireless communications, data collection and information processing in the integration of new distributed self-organizing. ZigBee technology is the most representative of the wireless sensor network, a unified technical standards, low cost, low power consumption, etc.. ZigBee technology applied to coal mine safety monitoring, which will effectively improve the level of coal mine safety production monitoring and management. In this paper ZigBee technology is built data collection monitoring system for wireless sensor networks in the intelligent monitoring system of coal mine. Using Zigbee wireless communication technology, the establishment based on wireless sensor network (WSN) of coal mine safety monitoring system has become a coal mine safety production and the demand of the modern management.

The scheduling indoor host real-time monitoring computer of coal mine monitoring and control system can detect the change of the environment. It is predict possible accident and danger through the intelligent expert knowledge base. The intelligent analysis can prevent accidents or expand, and can timely alarm and prompted evacuation of staff. After the accident can be timely for disaster relief and evacuation instructions. It has a great practical value to realize automation of production safety. Wireless network is adopted to improve the environmental monitoring. It makes the monitoring system to get rid of the limitations of traditional wired signal transmission way. It makes the monitoring system of the mobility and convenience of installation are increased greatly. It can monitors the gob, mechanized mining face large concentration of methane gas and other areas that is difficult to achieve. It achieves the full range of downhole environment, dynamic real-time monitoring. 
The industrial Ethernet and ring network architecture of remote control system, for each point, which can realize remote network control, can improve the management, monitoring, emergency situations. The remote control system is composed of wireless sensor network, industrial Ethernet and application of ring network. For each monitoring point, can realize the network remote control and improve the management, monitoring, emergency.

\section{System Construction}

The coal mine intelligent monitoring system, through the mine field of ZigBee nodes to collect a variety of wireless data, through the switch to downhole monitoring sites. The downhole monitoring stations adopts ring network connection that can communicates conveniently. In addition the system sets up a backup underground control and monitoring stations, to improve the reliability and safety of the system. Downhole monitoring stations has transmitted the data to upper monitoring machine by industrial Ethernet. Upper monitor machine based on the collection of information analyzes the data intelligently, makes the decision, issues directives to monitoring and controlling the work status of the entire mine for entered the best working conditions. The system consists of the monitoring layer, the Ethernet transmission layer and the field wireless network transmission layer. It includes wireless data acquisition subsystem based on ZigBee network, industrial Ethernet transmission subsystem and remote monitoring system. As shown in Fig. 1.

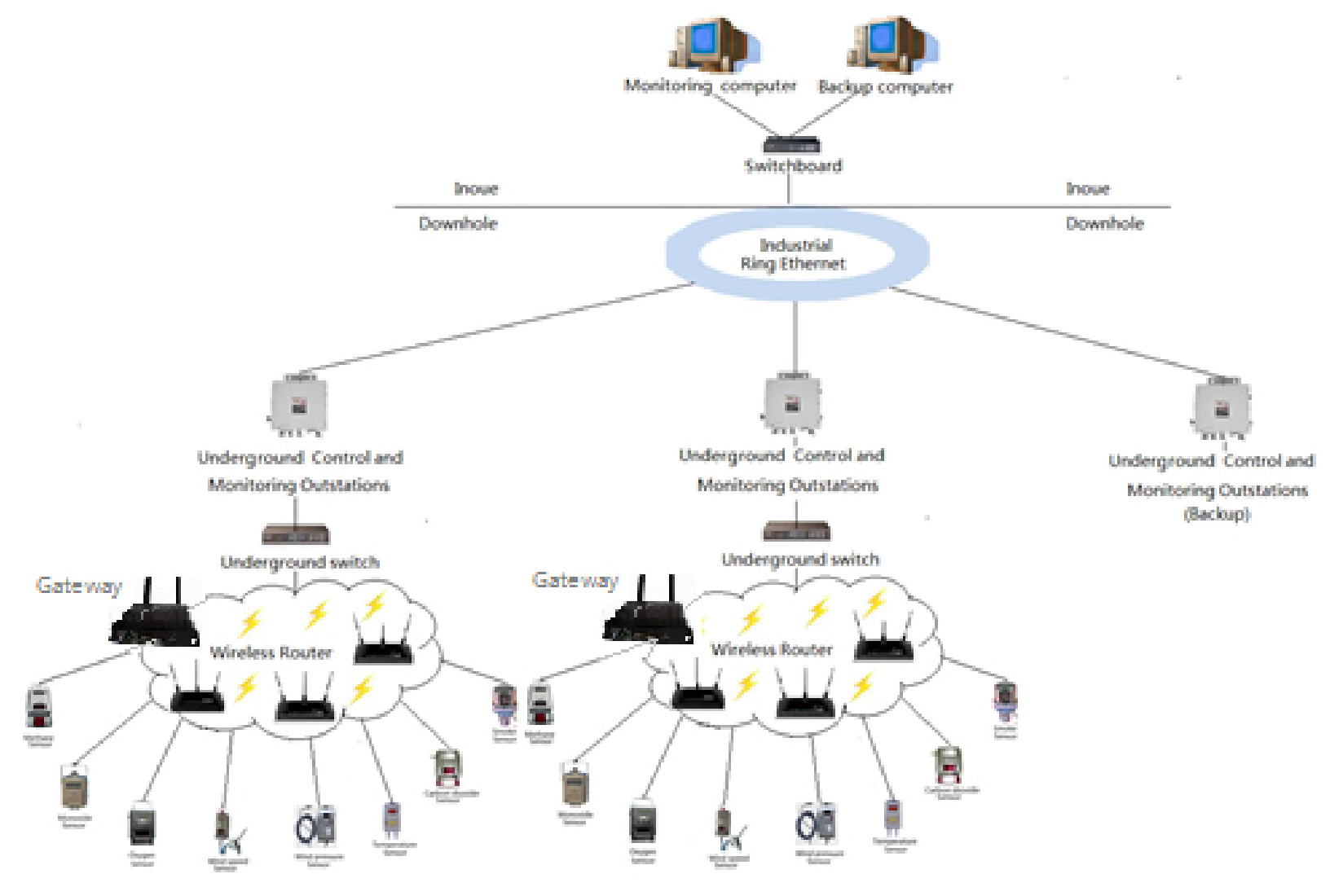

Fig. 1 System Structure.

The Wireless Network Transmission Layer. With the rapid development of wireless communication technology, in recent year's technology characteristics and advantage of ZigBee that has been in the short distance wireless transmission is obvious. In this paper, the Zig Bee, Wi-Fi, bluetooth, UWB, NFC several wireless networking technology performance were compared. 
Table 1. Short-range wireless communications technology.

\begin{tabular}{|c|c|c|c|c|c|}
\hline Technology item & ZigBee & Wi-Fi & bluetooth & UWB & NFC \\
\hline $\begin{array}{c}\text { Communication } \\
\text { distance }\end{array}$ & $20-200 \mathrm{~m}$ & $20-200 \mathrm{~m}$ & $10 \mathrm{~m}$ & $1-40 \mathrm{~m}$ & $0.1 \mathrm{~m}$ \\
\hline Transmission rate & $100 \mathrm{Kbps}$ & $11-54 \mathrm{Mbps}$ & $1 \mathrm{Mbps}$ & $48-100 \mathrm{Mbps}$ & $424 \mathrm{k}$ \\
\hline $\begin{array}{c}\text { Operating } \\
\text { Frequency }\end{array}$ & $2.4 \mathrm{GHz}$ & $2.4 \mathrm{GHz}$ & $2.4 \mathrm{GHz}$ & $3.1 \mathrm{GHz}-10.6 \mathrm{GHz}$ & $13.56 \mathrm{MHz}$ \\
\hline $\begin{array}{c}\text { International } \\
\text { standard }\end{array}$ & $\begin{array}{c}\text { IEEE } \\
802.15 .4\end{array}$ & $\begin{array}{c}\text { IEEE } \\
802.11 \mathrm{~b}\end{array}$ & $\begin{array}{c}\text { IEEE } \\
802.15 .1 \mathrm{x}\end{array}$ & Not established & $\begin{array}{c}\text { ISO/IEC18092 } \\
\text { ISO/IEC21481 }\end{array}$ \\
\hline $\begin{array}{c}\text { Power } \\
\text { consumption }\end{array}$ & $5 \mathrm{~mA}$ & uncertain & $20 \mathrm{~mA}$ & $20 \mathrm{~mA}$ & $10 \mathrm{~mA}$ \\
\hline $\begin{array}{c}\text { transmission } \\
\text { mode }\end{array}$ & $\begin{array}{c}\text { point-to- } \\
\text { multipoint }\end{array}$ & $\begin{array}{c}\text { point-to- } \\
\text { point }\end{array}$ & $\begin{array}{c}\text { point-to- } \\
\text { multipoint }\end{array}$ & $\begin{array}{c}\text { point-to- } \\
\text { multipoint }\end{array}$ & $\begin{array}{c}\text { point-to- } \\
\text { point }\end{array}$ \\
\hline
\end{tabular}

By contrast in Table 1, the ZigBee technology has great advantage in networking, power consumption and so on. It has a large capacity, good compatibility, stable and reliable, etc. Therefore, the system selects the Zig Bee technology form a wireless sensor network.

The layer collects and manages real-time data of each coal mine safety production subsystem. Through the ZigBee wireless sensor network it achieves the remote wireless data communication and provides basic data for intelligent decision. This layer selected a series of sensors that conforms to the law of the People's Republic of China coal industry standard "coal mine environment monitoring sensor for general technical conditions (MT 443-1995), ". As shown in the Fig. 2.
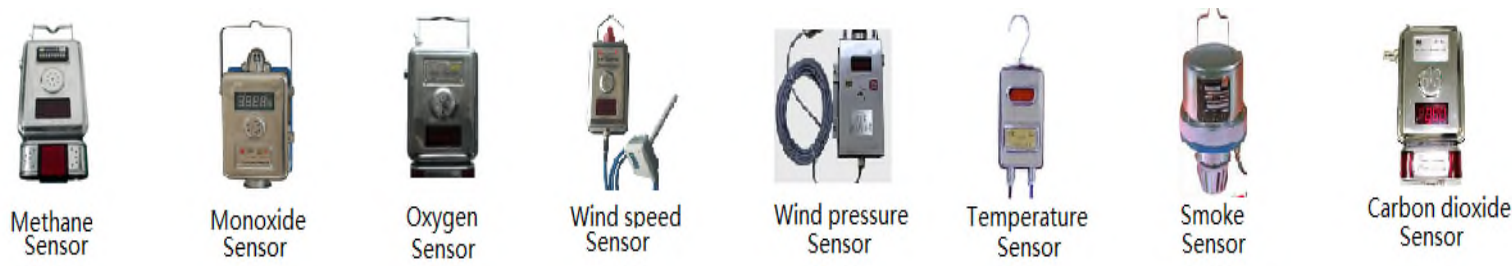

Fig. 2 Sensors.

Ethernet Transport Layer. Ethernet transport layer uses the optical fiber Ethernet ring network. Optical fiber transmission has many other advantages that are low attenuation, bandwidth, good frequency characteristics, and strong anti-electromagnetic interference capability. It greatly improve the quality of the signal transmission and reliability of transmission. The transmission distance is about a few tens of kilometers without relay, compensation. As the optical fiber communication technology advances, cable, optical devices and optical modulation transmission equipment costs continue have been declining. And because the fiber optic transmission of optical signals instead of electrical signals, it has excellent safety features, for risk and the coal mine complex environment. Using optical fiber transmission has obvious advantages.

Ethernet is widely used, low cost, high speed communications, rich software and hardware resources, sustainable development potential, ease of access. In many ways its technology, speed and price have an unparalleled advantage to other networks. With the improvement of the Ethernet performance and Ethernet technology to solve the problem of real-time Ethernet technology, industrial Ethernet as a new industry control system, has got more and more widely used in many industrial fields. It gradually become stable and mature technology. The industrial Ethernet control system is applied to the coal mine, which can greatly improve the rate of coal mine communication network, reduce the amount of communication lines and equipment maintenance. At the same time it can provide a variety of standard interface. The mine communication system theory and the technical increases to a new level. The ring Industrial Ethernet technology is based on Ethernet development. It inherits the Ethernet speed, low-cost advantages, which provides a links to data transmission on the network and improves network reliability. It is the industrial control ideal for areas of information transmission network. 
Ethernet transport layer uses the GYSTS type flame retardant fiber for mine as a transmission medium. To ensure good compatibility and scalability, Ethernet TCP / IP technology is used as a communication standard of the whole system. The Ethernet sets the high-speed ring network, and the main link uses gigabit fiber. It has Very high data transfer rate and strong network adaptability.

Monitoring Layer. Upper monitor the machine by industrial Ethernet to receive information from the remote monitory point. After receiving the information the upper monitor machine can selected and adjust the relevant procedure according to the actual circumstances of the remote monitor control points. Also it can make the use of the expert Knowledge to make intelligent decisions, such as carbon monoxide concentration, excess temperature, mine fire, natural seam tape conveyor belt fire accident may occur, fire warning should be given.

\section{System Design}

Intelligent Control design. Host monitoring machine keeps the expert knowledge base, and directly impacts the quality of the knowledge base system quality. Knowledge base includes two kinds of knowledge: one is the basic theory and principle, the other is accumulated expertise based on direct experience and indirect experience. The first step in building a knowledge base is to collect these two areas of knowledge, after finishing, the identification of indicators.

\section{Gas Monitoring and Protection design.}

Table 2. Mine CO maximum allowable concentration.

\begin{tabular}{|l|l|l|}
\hline $\mathrm{CO}$ & $<0.0024$ & Highly toxic, Concentration of $13 \% \sim 75 \%$ with explosive \\
\hline
\end{tabular}

Table 3. The methane sensor alarm concentration, power-off concentration, restore power concentration and power-off range.

\begin{tabular}{|c|c|c|c|c|}
\hline $\begin{array}{c}\text { Methane sensor set } \\
\text { location }\end{array}$ & $\begin{array}{c}\text { Alarm } \\
\text { concentration }\end{array}$ & $\begin{array}{c}\text { Power-off } \\
\text { concentration }\end{array}$ & $\begin{array}{c}\text { Restore } \\
\text { power } \\
\text { concentration }\end{array}$ & Power-off range \\
\hline $\begin{array}{c}\text { Low and high gas coal } \\
\text { mining working face }\end{array}$ & $\geq 1.0 \% \mathrm{CH} 4$ & $\geq 1.5 \% \mathrm{CH} 4$ & $<1.0 \% \mathrm{CH} 4$ & $\begin{array}{c}\text { Working face and return } \\
\text { air lane all non } \\
\text { intrinsically safe } \\
\text { electrical equipment }\end{array}$ \\
\hline $\begin{array}{c}\text { Coal mining face } \\
\text { return airway of Mine } \\
\text { Monitoring System }\end{array}$ & $\geq 1.5 \% \mathrm{CH} 4$ & $\geq 1.5 \% \mathrm{CH} 4$ & $<1.5 \% \mathrm{CH} 4$ & $\begin{array}{c}\text { Working face and return } \\
\text { air lane all non } \\
\text { intrinsically safe } \\
\text { electrical equipment }\end{array}$ \\
\hline $\begin{array}{c}\text { The sensor is } \\
\text { connected in series } \\
\text { ventilation in coal } \\
\text { mining face into the } \\
\text { wind Lane }\end{array}$ & $\geq 0.5 \% \mathrm{CH} 4$ & $\geq 0.5 \% \mathrm{CH} 4$ & $\begin{array}{c}\text { All non-intrinsically safe } \\
\text { electrical equipment are } \\
\text { connected in series of } \\
\text { coalface and into the } \\
\text { return air lane }\end{array}$ \\
\hline $\begin{array}{c}\text { The sensor is } \\
\text { connected in series } \\
\text { with the front part of } \\
\text { the driving working } \\
\text { face with ventilation. }\end{array}$ & $\geq 0.5 \% \mathrm{CH} 4$ & $\geq 0.5 \% \mathrm{CH} 4$ & $<0.5 \% \mathrm{CH} 4$ & $\begin{array}{c}\text { All non-intrinsically safe } \\
\text { electrical equipment are } \\
\text { connected in series in the } \\
\text { roadway. }\end{array}$ \\
\hline $\begin{array}{c}\text { The air inlet side back } \\
\text { to the mechanical and } \\
\text { electrical equipment } \\
\text { room }\end{array}$ & $\geq 0.5 \% \mathrm{CH} 4$ & $\geq 0.5 \% \mathrm{CH} 4$ & $<0.5 \% \mathrm{CH} 4$ & $\begin{array}{c}\text { All non-intrinsically safe } \\
\text { electrical equipment of in } \\
\text { mechanical and electrical } \\
\text { equipment room }\end{array}$ \\
\hline
\end{tabular}


The mine methane, carbon monoxide, carbon dioxide, oxygen is monitored that use the expert knowledge for intelligent judgment. From expert experience that the airflow into the mining, the oxygen concentration does not less than $20 \%$, carbon dioxide concentration does not exceed $0.5 \%$, Mine CO maximum allowable concentration as shown in Table 2, the methane sensor alarm concentration, power-off concentration, restore power concentration and power-off range as shown in Table 3. If the signal is unusual, the system will be automatic power off, alarm and lockout, to prevent accidents and to expand.

Temperature Monitoring and Protection Design. "Coal Mine Safety Regulations" provides that mine production coalface air temperature must not exceed $26{ }^{\circ} \mathrm{C}$; electromechanical Chamber air temperature must not exceed $30{ }^{\circ} \mathrm{C}$. Mining face air temperature exceeds $30{ }^{\circ} \mathrm{C}$, if the electromechanical Chamber air temperature exceeds $34{ }^{\circ} \mathrm{C}$, cooling measures must be taken to gradually resolve.

Smoke Monitoring and Early Warning Design. Smoke inside the mine is monitored, when the smoke concentration reaches a certain value, the early warning signal is given.

Wind Speed and Air Pressure Monitoring and Fault Diagnosis Design. Through continuous monitoring mine ventilation roadway wind speed device, mine fan, throttle, closed roadway, pressure ventilation devices of the ventilation tunnel. "Coal mine safety regulations" regulation, the main wind speed should not exceed $8 \mathrm{~m} / \mathrm{s}$ into the lane, the mining face, coal roadway in advance and half coal roadway, the minimum allowable wind speed for $S$., maximum allowable speed is $4 \mathrm{~m} / \mathrm{S}$; Excavation in rock roadway minimum allowable speed is $0.15 \mathrm{~m} / \mathrm{s}$, maximum allowable wind speed is $4 \mathrm{~m} / \mathrm{S}$; Other ventilation roadway minimum allowable wind speed is $0.15 \mathrm{~m} / \mathrm{s}$. If it is found that wind speed or wind anomalies, the system can give fault possible reasons, and inform the relevant maintenance personnel for processing. From expert experience that the allowed wind speed in the roadway as shown in Table 4.

Table 4 . The allowed wind speed in the roadway.

\begin{tabular}{|c|c|c|}
\hline \multirow{2}{*}{ Roadway name } & \multicolumn{2}{|c|}{ The allowable wind speed } \\
\cline { 2 - 3 } & Min & Max \\
\hline The main inlet and return Roadway & 0.25 & 8 \\
\hline Haulage roadway, mining area, return air lane & 0.25 & 6 \\
\hline Coal face, Coal Lane Tunneling, semi coal and rock roadway & 0.25 & 4 \\
\hline
\end{tabular}

Upper monitor obtains the expert mode and adjusts controlled object according to the best working curve. If the client sends commands, the computer will receive instructions and after analysis, call related expert mode, issue instructions according to needs and rules. Because this system could receive relevant information through the computer to make intelligent control decisions which can achieve security features.

System Security Design. System security Settings is the guarantee of the system safety work. Before login system operators need to pass a series of authentication. Host monitoring machine set the login operator name, the operator password, the role of the operator in the corresponding database file. Character design can be divided into three levels, the super administrator, administrator, operators. Remote users log in through the network, will be able to enter the password in the system login window, and the system function specific operations depends on the user's role. If you are a super administrator may have access to all system functions, ordinary administrators can operate the system, but you cannot add and modify user information, general operator can view and browse, can not make decisions to operate.

System Software Design. The system program design based on C\# platform and background database SQL Server2014. Monitoring software module will collect data transmission up to give decision-making using expert knowledge to prevent the happening of the accident, eliminate safety hidden trouble. 


\section{Conclusions}

In this paper, the intelligent monitoring system of coal mine based on the ZigBee wireless sensor network, in the practical application of a certain coal mine shows that by the concentration of methane concentration, concentration of carbon monoxide, carbon dioxide, oxygen concentration, wind speed, wind pressure, smoke, temperature and other indicators of real-time monitoring and use expert knowledge to make intelligent decisions, can effectively prevent the fire gases, temperature, smoke and caused other accidents. The wireless sensor network plays an important role in the system, with the improvement of the communications industry development and management requirements, the application of wireless networks will be more widely used. Designed man-machine interface and intelligent control decision-making procedures with $\mathrm{C \#}$, have the friendly man-machine interface. The system has the scalability, security and reliability.

\section{References}

[1] B. Cheng, X. Cheng and J. Chen, Lightweight monitoring and control system for coal mine safety using REST style. ISA T. 54 (2014) 229-239.

[2] J. C. Vazquez, V. Champac and A. M. Ziesemer et. Delay sensing for long-term variations and defects monitoring in safety-critical applications, Analog. Integr. Circ. S. 70(2) (2012) 249-263.

[3] R. Stanica, E. Chaput and A. L. Beylot. Reverse back-off mechanism for safety vehicular ad hoc networks, Ad Hoc Netw. 16 (2014) 210-224.

[4] D. S. Simbeye, J. M. Zhao and S. F. Yang, Design and deployment of wireless sensor networks for aquaculture monitoring and control based on virtual instruments, Comput. Electr. Agr. 102 (2014) $31-42$.

[5] P. Patel and D. Cassou, Enabling high-level application development for the Internet of Things. J. Syst. Softw. 103 (2015) 62-84.

[6] Z. Y. Liu, Hardware Design of Smart Home System based on ZigBee Wireless Sensor Network, AASRI Procedia, 8 (2014) 75-81.

[7] G. Liang, Control and communication co-design: Analysis and practice on performance improvement in distributed measurement and control system based on fieldbus and Ethernet. ISA T. 54 (2014) 169-192. 